\title{
Hemoglobin-mediated selenium export from red blood cells
}

Mamoru Haratake $\cdot$ Katsuyoshi Fujimoto $\cdot$ Ritsuko Hirakawa $\cdot$ Masahiro Ono $・$ Morio Nakayama

Graduate School of Biomedical Sciences, Nagasaki University, 1-14 Bunkyo-machi, Nagasaki, 8528521 Japan, e-mail: haratake@nagasaki-u.ac.jp for M. Haratake, morio@nagasaki-u.ac.jp for M. Nakayama, Fax: +81-95-819-2893

\begin{abstract}
On the basis of the fact that selenium (Se) from selenite binds to hemoglobin ( $\mathrm{Hb}$ ), we investigated the missing process in the selenium export from red blood cells (RBCs), i.e., the transfer of selenium bound to $\mathrm{Hb}$ to $\mathrm{RBC}$ membrane proteins. To elucidate the molecular events of the $\mathrm{Hb}$ associated selenium export from $\mathrm{RBC}$, an $\mathrm{Hb}$-Se complex was synthesized from thiol-exchange of Cys$\beta 93$ in $\mathrm{Hb}$ with penicillamine-substituted glutathione selenotrisulfide, as a model of major metabolic intermediates, and then interactions between the Hb-Se complex and $\mathrm{RBC}$ inside-out vesicles (IOVs) were examined. Selenium bound to $\mathrm{Hb}$ was transferred to the IOV membrane on the basis of the intrinsic interactions between $\mathrm{Hb}$ and the cytoplasmic domains of Band 3 protein (CDB3). The observed selenium transfer was inhibited by the pretreatments of IOVs with iodoacetamide and the $\alpha$ chymotrypsin digestion, indicating that the $\mathrm{Hb}$ mediates the selenium transfer to the thiol groups of CDB3. In addition, it was found that deoxygenated $\mathrm{Hb}$ with a high binding affinity for $\mathrm{CDB} 3$ more favorably transferred selenium to the IOV membranes than oxygenated $\mathrm{Hb}$ with a low affinity. When selenium export from $\mathrm{RBC}$ to the plasma was examined by continuously introducing nitrogen gas, the selenium export rate was promoted with an increase in the rate of deoxygenated $\mathrm{Hb}$. Overall, these data suggested that $\mathrm{Hb}$ could possibly play a role in the selenium export from $\mathrm{RBC}$ treated with selenite in an oxygen-linked fashion.
\end{abstract}

Keywords Band 3 protein $\cdot$ Hemoglobin $\cdot$ Inside-out vesicle $\cdot$ Red blood cell $\cdot$ Selenium

Abbreviations $N$-CPD: Amino-terminal cytoplasmic domain $\cdot \mathrm{AE} 1$ : Anion exchanger $1 \cdot C$-CPD: Carboxy-terminal cytoplasmic domain $\cdot \alpha$-Chy: $\alpha$-Chymotrypsin $\cdot$ CDB3: Cytoplasmic domains of Band 3 protein - DAN: 2,3-Diaminonaphtalene - DIDS: 4,4'-Diisothiocyanato-2,2'-stilbene disulfonate • DTNB: 5,5'-Dithiobis (2-nitrobenzoic acid) -GSH: Glutathione - GPx: Glutathione peroxidase • 
GSSeSG: Glutathione selenotrisulfide •GPA: Glycophorin A•Hb: Human hemoglobin • IOV: Inside-out vesicle $\cdot$ MALDI-TOF: Matrix-assisted laser desorption ionization-time of flight $\cdot$ Pen: L-Penicillamine • PenGSH: L-Penicillamine-substituted glutathione ( $\gamma$-L-Glu-L-Pen-Gly) • RBC: Red blood cell

\section{Introduction}

Oxygen is essential for all higher forms of animal life. Vertebrates have evolved with two principal mechanisms for supplying their peripheral tissues/cells with a continuous and adequate flow of oxygen to acquire much energy from glucose. The first mechanism is a circulatory system that actively delivers oxygen to the peripherals. The second is the use of oxygen-carrying molecules to overcome the limitation imposed by the low solubility of oxygen in water. Hemoglobin $(\mathrm{Hb})$ molecules in red blood cells (RBCs) serve as the oxygen carrier from the respiratory to peripheral tissues and also play a vital role in the transport of cellular waste carbon dioxide in the opposite direction [1]. On the other hand, selenium is also an essential trace element in mammals and is broadly distributed over the entire body and incorporated into selenoproteins in the form of selenocysteine that is known the 21 st amino acid. The family of selenium-dependent glutathione peroxidases (GPx-1, GPx-2, GPx-3, GPx-4 \& GPx-6) is the best-known example of the selenoproteins [2]. These enzymes play a critical role in the antioxidant defense against the deleterious actions of free radicals and lipid peroxides that unavoidably occur due to the oxygen utilization [3]. The selenium element as the central building block of GPxs is thought to be delivered to the entire body via the bloodstream.

In humans, the chemical form of selenium from food sources is mainly organic selenomethionine and selenocysteine, while inorganic selenite $\left(\mathrm{SeO}_{3}{ }^{2-}\right)$ is rare but an effective source compound most frequently used in the selenium supplementation for medical treatments. Selenite is immediately taken up from the plasma into RBC through the Band 3 protein (anion exchanger 1) and then returned to the plasma after the reductive metabolism in RBC [4,5]. However, little is known about the definitive delivery mechanisms of selenium from selenite after the RBC uptake. It has been speculated further that reductive metabolites such as selenide excreted into the bloodstream are bound to albumin and transferred to tissues/cells. If the oxygen-carrying $\mathrm{Hb}$ molecule participates in the selenium delivery to the peripheral blood and/or tissues in order to extinct the harmful substances that are generated by the accompanying oxygen utilization, it is likely to be a compensatory function of $\mathrm{Hb}$. In human $\mathrm{Hb}$, the $\beta$ chain contains a thiol group (Cys- $\beta 93)$ that probably reacts with reductive metabolites of selenite. This thiol group is highly conserved among species while its actual physiological function has remained unknown. In this study, we synthesized a metabolic intermediate of selenium in RBCs as a chemical 
tool to reveal the missing process, i.e., the transfer of selenium bound to hemoglobin to RBC membrane proteins.

\section{Materials and methods}

Materials

L-Pen and iodoacetamide were obtained from Tokyo Chemical Industry Co., Ltd. The human hemoglobin was from Sigma Co. \{oxy-Hb : deoxy-Hb : ferri-Hb = $6: 9: 86$ (UV-VIS photometry), Hb purity; 98.9\%, the number of reactive thiol groups determined by the DTNB [5,5'-dithiobis(2nitrobenzoic acid)] method; 1.45 per Hb tetramer\} method. $\alpha$-Chymotrypsin (from bovine pancreas, 35-65 units/mg) was purchased from Nacalai Tesque, Inc. Sinapinic acid used as a matrix substance

for MALDI-TOF mass spectrometry was obtained from Fluka. All other chemicals were of commercial reagent or special grades and used as received.

Determination of selenium and protein concentrations

The selenium concentrations were fluorometrically determined using 2,3-diaminonaphtalene (DAN) after the digestion with a one to five mixture by volume of perchloric acid and nitric acid [6]. The selenium standard solution [1,000 ppm as selenium (IV) dioxide in $0.5 \mathrm{M}$ nitric acid] for the fluorometry was obtained from Kanto Chemical Co., Inc. The protein concentrations were measured by BCA protein assay [7].

Preparation of RBCs and oxy-Hb

Fresh human venous blood was collected in a heparinized vacutainer tube. Each sample was centrifuged at $1,400 \mathrm{~g}$ for $10 \mathrm{~min}$ at room temperature, and the plasma, buffy coat and upper $10 \%$ of the $\mathrm{RBC}$ layers were removed by aspiration. The precipitated RBCs were washed three times with isotonic phosphate buffer ( $\mathrm{pH}$ 7.4). The isolated RBCs were hemolyzed with 40 volumes of $5 \mathrm{mM}$ phosphate solution ( $\mathrm{pH} \mathrm{8)}$, and centrifuged at 22,000 $\mathrm{g}$ for $10 \mathrm{~min}$. The supernatant was dialyzed against $0.5 \mathrm{mM}$ phosphate solution ( $\mathrm{pH}$ 8) using a Spentra ${ }^{\circledR} /$ Por Membrane (molecular weight cutoff; 6-8 kDa) at $4{ }^{\circ} \mathrm{C}$. The transition state of the purified oxy-Hb was measured from visible absorption spectra (from 560 to $630 \mathrm{~nm}$ ) according to the method of Zijistra et al. [8] by UV-VIS photometry (oxy-Hb : deoxy-Hb : 
ferri-Hb $=87: 10: 3$, the number of reactive thiol groups determined by the DTNB method; 1.69 per $\mathrm{Hb}$ tetramer).

Analysis of selenium distribution in selenite-treated RBCs

The isolated RBCs were treated with varying concentrations of selenite $(0.8-80 \mu \mathrm{M})$ in isotonic phosphate buffer ( $\mathrm{pH} \mathrm{7.4)}$ at $37{ }^{\circ} \mathrm{C}$ for $10 \mathrm{~min}$ [hematocrit $\left.20 \%(\mathrm{v} / \mathrm{v})\right]$. The RBCs were hemolyzed by the addition of two volumes of deionized water, and centrifuged at $28,000 \mathrm{~g}$ for $1 \mathrm{~h}$. The supernatant and the red pellet were then separated. Furthermore, the supernatant was diluted and ultrafiltered using an Ultrafree ${ }^{\circledR}$-MC (30 kDa nominal molecular weight limit). The selenium contents of the supernatant (cytosol, whole), the filtrate (cytosol, molecular weight less than $30 \mathrm{kDa}$ ), and the red pellets (the plasma membrane) were determined. To investigate the membrane-bound selenium in detail, the selenite-treated RBCs were hemolyzed by the addition of 40 volumes of $5 \mathrm{mM}$ phosphate solution $(\mathrm{pH}$ 8). The hemolysate was centrifuged at $22,000 \mathrm{~g}$ for $15 \mathrm{~min}$ and the supernatant was aspirated. The pellets were washed three times with $5 \mathrm{mM}$ phosphate solution $(\mathrm{pH} \mathrm{8})$ and once with $0.5 \mathrm{mM}$ phosphate solution ( $\mathrm{pH}$ 8). White unsealed ghosts were obtained and their selenium and protein concentrations were determined.

Synthesis of PenGSSeSGPen

Penicillamine-substituted glutathione ( $\gamma$-L-Glu-L-Pen-Gly, PenGSH) was synthesized by the conventional liquid-phase synthesis reaction. Purified PenGSH had a 1.08 thiol group/molecule when determined by the DTNB method. ${ }^{1} \mathrm{H}$ NMR $\left(\mathrm{D}_{2} \mathrm{O}\right): 1.43(s, 3 \mathrm{H}), 1.49(s, 3 \mathrm{H}), 2.14(q, 2 \mathrm{H}, \mathrm{J}=7.2 \mathrm{~Hz})$, $2.57(t, 2 \mathrm{H}, \mathrm{J}=7.8 \mathrm{~Hz}), 3.77(t, 1 \mathrm{H}), 3.87(s, 2 \mathrm{H}), 4.47(s, 1 \mathrm{H})$. FAB MS: calcd for $\mathrm{C}_{12} \mathrm{H}_{21} \mathrm{~N}_{3} \mathrm{O}_{6} \mathrm{~S} \mathrm{~m} / \mathrm{z}$ 336.1, found: 336.0. Anal. calcd for $\mathrm{C}_{12} \mathrm{H}_{21} \mathrm{~N}_{3} \mathrm{O}_{6} \mathrm{~S} \cdot \mathrm{CF}_{3} \mathrm{COOH} \cdot 2 \mathrm{H}_{2} \mathrm{O} \mathrm{C}, 34.64 ; \mathrm{H}, 5.40 ; \mathrm{N}, 8.66$, found: C, 35.89; H, 5.47; N, 9.01. PenGSH (10 mM) was allowed to react with selenious acid (2.5 $\mathrm{mM}$ ) in deionized water with stirring for $12 \mathrm{~h}$ at room temperature. The resultant was chromatographed on a COSMOSIL 5C18-AR-II at the flow rate of $7 \mathrm{~mL} / \mathrm{min}$ with a detection wavelength of $210 \mathrm{~nm}$. The column was programmed with a 70-min linear gradient from 100 to $50 \%$ of eluent A [10\% (v/v) acetonitrile in water containing $0.005 \%(\mathrm{v} / \mathrm{v})$ trifluoroacetic acid] in eluent B (acetonitrile). The peak assigned to PenSSeSPen was fractionated, and then followed by lyophilization. ${ }^{1} \mathrm{H}$ NMR $\left(\mathrm{D}_{2} \mathrm{O}\right): \delta 1.44(s, 3 \mathrm{H}), 1.49(s, 3 \mathrm{H}), 2.10(m, 2 \mathrm{H}), 2.51(t, 2 \mathrm{H}, \mathrm{J}=7.5 \mathrm{~Hz}), 3.72-3.78(\mathrm{~m}, 3 \mathrm{H})$, 4.55 (s, 1H), MALDI-TOF MS: calcd for $\mathrm{C}_{24} \mathrm{H}_{40} \mathrm{~N}_{6} \mathrm{O}_{12} \mathrm{~S}_{2}{ }^{80} \mathrm{Se} \mathrm{m} / \mathrm{z}$ 748.1, found: 749.8. Anal. calcd for 
$\mathrm{C}_{24} \mathrm{H}_{40} \mathrm{~N}_{6} \mathrm{O}_{12} \mathrm{~S}_{2} \mathrm{Se} \cdot 2 \mathrm{CF}_{3} \mathrm{COOH} \cdot 4 \mathrm{H}_{2} \mathrm{O} \mathrm{C}, 32.10 ; \mathrm{H}, 4.81 ; \mathrm{N}, 8.02 ; \mathrm{Se}, 7.54$, found C, 32.08; H, 4.56; N, 7.93, Se, 7.33. $\lambda_{\max }$ in deionized water: $268 \mathrm{~nm}\left(\varepsilon_{\mathrm{mM}}=1.60\right)$ (Fig. S1).

Preparation of $\mathrm{Hb}-\mathrm{Se}$ complex

PenGSSeSGPen $(0.5 \mathrm{mM})$ was combined with $\mathrm{Hb}(50 \mathrm{mM}$ as tetramer $)$ in $0.5 \mathrm{mM}$ phosphate solution ( $\mathrm{pH}$ 7.4). The mixture was incubated for $10 \mathrm{~min}$ at $37^{\circ} \mathrm{C}$, and then the unreacted PenGSSeSGPen was removed by passing through a Sephadex G-50 (fine) column equilibrated with $0.5 \mathrm{mM}$ phosphate solution ( $\mathrm{pH}$ 7.4). The ferri-Hb and ferri-Hb-Se concentrations were measured using a molar extinction coefficient of $\mathrm{Hb}$ at $407 \mathrm{~nm}\left(\varepsilon=352.3 \mathrm{mM}^{-1} \mathrm{~cm}^{-1}\right)$. The oxy-Hb concentrations and the transition states of the prepared $\mathrm{Hb}-\mathrm{Se}$ complex were measured by UV-VIS photometry (ferri-Hb-Se; oxy-Hb : deoxy-Hb : ferri-Hb = $10: 3: 87$, oxy-Hb-Se; oxy-Hb : deoxy-Hb : ferri-Hb=72:0:28). The purified $\mathrm{Hb}-\mathrm{Se}$ complex contained 0.78 selenium/Hb tetramer.

Preparation of IOV and selenium transfer experiment

The IOVs were prepared from the white ghosts according to the method of Steck and Kant with slight modifications [9]. The apparent purity of the used IOVs was estimated to be $87.9 \pm 0.6 \%$ (mean \pm s. e. m.) from the determination of the acetylcholinesterase activity. The IOVs were mixed with the Hb-Se complex in $10 \mathrm{mM}$ phosphate buffer ( $\mathrm{pH} \mathrm{6)}$ ) at ambient temperature, and the mixture was centrifuged at $22,000 \mathrm{~g}$ for $15 \mathrm{~min}$. The binding affinity of the $\mathrm{Hb}$-Se complex with $\mathrm{Hb}$ to IOV was compared using the Langmuir type binding equation. In a study of the selenium transfer, the mixture of the Hb-Se complex and IOV was centrifuged at $22,000 \mathrm{~g}$ for $15 \mathrm{~min}$, and then the precipitated IOVs were washed with $20 \mathrm{mM}$ phosphate buffer $(\mathrm{pH} 8)$ containing $0.5 \mathrm{M}$ sodium chloride to remove the IOV-bound $\mathrm{Hb}$ and $\mathrm{Hb}$-Se complex. The released $\mathrm{Hb}$ amounts in the washing buffer and a SDS-PAGE analysis of the IOV (Fig. S2) indicated that $\mathrm{Hb}$ and the $\mathrm{Hb}-\mathrm{Se}$ complex were completely washed out from the IOV membranes. The Hb-Se complex solutions of various transition states (oxy-Hb-Se content; 10 to $70 \%$, ferri-Hb-Se content; 30 to $90 \mathrm{~mol} \%$ ) were prepared by mixing of the oxy-Hb-Se and ferri-Hb-Se.

Selenium export experiment from selenite-treated RBCs to the plasma

The isolated RBCs were treated with selenite $(8 \mu \mathrm{M})$ in isotonic phosphate buffer $(\mathrm{pH} 7.4)$ at $37{ }^{\circ} \mathrm{C}$ for $10 \mathrm{~min}$. The plasma was separately placed in a tightly sealed glass vessel, and was exposed to gentle 
$\mathrm{N}_{2}$ gas bubbling at $37{ }^{\circ} \mathrm{C}$ for $30 \mathrm{~min}$. The $\mathrm{RBC}$ suspension was combined with the plasma in the sealed glass vessel [hematocrit $50 \%(\mathrm{v} / \mathrm{v})$ ], and then incubated with $\mathrm{N}_{2}$ gas bubbling at $37{ }^{\circ} \mathrm{C}$. Aliquots of the $\mathrm{RBC}$ suspension were pipetted out at appropriate time intervals and centrifuged at $1,400 \mathrm{~g}$ and $4{ }^{\circ} \mathrm{C}$ for 10 min to separate it from the plasma. The selenium contents in the RBCs and the plasma were separately determined.

Statistical analysis

All data were presented as the mean \pm s. e. $m .(n=5$ or more $)$. Statistical analyses were performed using a program PRISM 4 (GraphPad Software Inc.). Multiple mean values were compared by a oneor two-way ANOVA with a Bonferroni post-hoc test. Comparisons were considered statistically significant at $P<0.05$.

\section{Results and discussion}

The hemolysate of RBC was separated into three fractions [low $(<30 \mathrm{kDa})$ and high $(>30 \mathrm{kDa})$ mass fractions, and the plasma membrane] and the selenium contents of each fraction were determined. Represented in Fig. 1 (A) is selenium distributions in RBC treated with varying selenite concentrations. Most of the selenium (>95\%) in the RBC hemolysate was found in the high mass fraction, namely $\mathrm{Hb}$, and the rest was in the low mass fraction and the plasma membrane. This selenium distribution was similar to each other for the three different selenite concentrations used in the RBC treatments. The selenium distributions remained the same up to $3 \mathrm{~h}$ after the uptake of selenite into the $\mathrm{RBC}$, which demonstrates that most of selenium is stably bound to $\mathrm{Hb}$. The selenium contents in the plasma membrane increased with an increase in the selenite concentration used for the treatment of RBC, although the distribution rate of selenium in the RBC was very low [Fig. 1 (B)].

Painter reported that the reaction of selenite with low mass thiol-containing compounds (RSH) yielded selenotrisulfide ( $\mathrm{RSSeSR})$ in vitro $\left(\mathrm{SeO}_{3}{ }^{2-}+4 \mathrm{R}-\mathrm{SH} \rightarrow \mathrm{R}-\mathrm{SSeS}-\mathrm{R}+\mathrm{R}-\mathrm{SS}-\mathrm{R}+3 \mathrm{H}_{2} \mathrm{O}\right)[10]$. Recently, glutathione selenotrisulfide (GSSeSG) was actually identified in a yeast extract by mass spectrometric techniques [11]. Since $\mathrm{Hb}$ did not allow the forming of $\mathrm{Hb}$ selenotrisulfide (HbSSeSHb) in the reaction with selenite probably due to a steric hindrance, the Painter reaction with glutathione (GSH) could also be involved in the metabolism of selenite in the RBC. We have demonstrated that selenotrisulfide preferentially reacts with the Cys- $\beta 93$ by the thiol exchange mechanism to form

$\mathrm{HbSSeSR}$, and selenium is not eliminated from $\mathrm{Hb}$ in the presence of GSH [12]. Consequently, 
selenite in the RBC is thought to transform into GSSeSG, and subsequently, GSSeSG could react with Cys- $\beta 93$ to form the HbSSeSG. These results are also consistent with previous observations that selenite is bound to $\mathrm{Hb}$ after undergoing the GSH-mediated reduction in $\mathrm{RBC}[4,5]$.

After the $\mathrm{RBC}$ was treated with selenite, selenium-bound $\mathrm{Hb}$ was not able to be directly characterized because the fraction of the selenium-bound $\mathrm{Hb}$ is fairly lower than that of the unbound one, in addition, the separation of the two species is also quite difficult. While the naturally occurring GSSeSG easily decomposes in vitro at physiological $\mathrm{pH}$ to generate the red elemental selenium $\left(\mathrm{Se}_{0}\right)$ that is not practically present in vivo $[13,14]$. An in vitro reaction of Hb with GSSeSG inevitably results in the generation of not only $\mathrm{HbSSeSG}$, but also unfavorable species such as the $\mathrm{Hb}^{-\mathrm{Se}_{0}}$ complex. To avoid this chemical diversity, we synthesized a new penicillamine-substituted glutathione selenotrisulfide [PenGSSeSGPen, Fig. 2 (A)] as a model of the metabolic intermediate GSSeSG. PenGSSeSGPen was isolatable and chemically stable in isotonic phosphate buffer $(\mathrm{pH} 7.4)$ at $37{ }^{\circ} \mathrm{C}$ for $4 \mathrm{~h}$ or longer without any degradation [Fig. 2 (B)]. PenGSSeSGPen and Hb were co-incubated in isotonic phosphate buffer $\left(\mathrm{pH} \mathrm{7.4)}\right.$ at $37^{\circ} \mathrm{C}$, and the unreacted PenGSSeSGPen was monitored by reversed-phase liquid chromatography. PenGSSeSGPen completely disappeared within 10 min after the incubation with $\mathrm{Hb}$ [Fig. 2 (C)]. The resulting material was subjected to a MALDI-TOF mass spectrometric analysis. In addition to the peaks assigned to the $\alpha$ - and $\beta$-chains (mass number 15191.9 and 15935.8 respectively), a separate peak appeared at mass number 16350.0 and its peak intensity increased with an increase in the PenGSSeSGPen/Hb molar ratio (Fig. 3). The mass number of 414.2, which is greater than the free $\beta$-chain, corresponded to that of the PenGSSe- moiety (calculated mass number for $\mathrm{C}_{12} \mathrm{H}_{20} \mathrm{~N}_{3} \mathrm{O}_{6} \mathrm{~S}_{2}{ }^{80} \mathrm{Se} 412.3$ ), suggesting the formation of Hb-SeSGPen (Hb-Se complex). These mass spectral data were identical to our previous work, in which penicillamine selenotrisulfide (PenSSeSPen) reacted only with the reactive Cys- $\beta 93$ via the thiol exchange mechanism [12]. In addition, no remarkable difference in the structural organization between the $\mathrm{Hb}-\mathrm{Se}$ complex and $\mathrm{Hb}$ was observed in the circular dichroism spectral data over the range from 190 to $350 \mathrm{~nm}$ (Fig. S3).

Since $\mathrm{Hb}$ molecules never pass through the $\mathrm{RBC}$ plasma membrane, selenium bound to $\mathrm{Hb}$ molecules must dissociate from $\mathrm{Hb}$ and then cross the plasma membrane for the selenium to be exported to the plasma. In addition, selenium release from the Hb-Se complex is not observed by glutathione treatment. It is known, however, that the amino-terminal cytoplasmic domain $(N-\mathrm{CPD}$, Met1-Pro403) of Band 3 offers the binding sites for $\mathrm{Hb}$ and the cytoskeletal proteins [15-21]. Band 3, a 911 amino acid integral membrane protein, catalyzes the electro-neutral exchange of $\mathrm{Cl}^{-} / \mathrm{HCO}_{3}{ }^{-}$ across the plasma membrane. This membrane protein also anchors a subpopulation of $\mathrm{Hb}$ molecules to RBC membranes, however, the functional significance of this behavior is not clear. 
We first examined whether the Hb-Se complex would bind to the inner surface of the RBC membrane, as the non-treated $\mathrm{Hb}$ does using the RBC inside-out vesicles (IOVs). When the binding constants of the $\mathrm{Hb}-\mathrm{Se}$ complex and $\mathrm{Hb}$ for IOV were estimated using the Langmuir type binding equation [22], the values obtained for the $\mathrm{Hb}-\mathrm{Se}$ complex and $\mathrm{Hb}$ were $2.10 \pm 0.43$ and $1.86 \pm 0.26$ $\left(\mu \mathrm{M}^{-1}\right)$, respectively (mean \pm s. e. m., $P=0.64$, Fig. S4). In similar experiments, we confirmed that PenGSSeSGPen and selenite were not interactive with the IOVs (Fig. S5). When the IOVs were treated with the $\mathrm{Hb}$-Se complex and thoroughly washed out with the washing buffer to remove the $\mathrm{Hb}$ bound to them, $2.58 \mathrm{pmol}$ selenium per $\mathrm{mg}$ of IOV protein remained on the IOVs (Fig. 4). Taking these results into account, the $\mathrm{Hb}-\mathrm{Se}$ complex is evidently capable of binding to the inner surface of the $\mathrm{RBC}$ membrane in a similar fashion to $\mathrm{Hb}$, and that $\mathrm{Hb}$ can deliver $\mathrm{Se}$ to the $\mathrm{RBC}$ membrane components.

Attempts were then made to elucidate the binding sites of selenium to be delivered by $\mathrm{Hb}$. The free cysteine residues (Cys201 and Cys317) of $N$-CPD are known to form a disulfide linkage with Cys$\beta 93$ under catalytic oxidative conditions [23]. X-ray crystal structure analysis indicates that the cytosolic part of one end of the Band 3 docks between the $\beta$ chains of the Hb molecules. Cys- $\beta 93$ of $\mathrm{Hb}$ is positioned near the potential target thiol groups in the Band 3 [16]. Recently, Stamler et al. demonstrated the concerted nitric oxide/oxygen systemic delivery by which nitric oxide is bound to Cys- $\beta 93$, and then delivered to Cys201 and Cys317 of $N$-CPD based on the intrinsic interactions of $\mathrm{Hb}$ with $N$-CPD $[24,25]$.

The pretreatment of IOV with iodoacetamide, a thiol-alkylating agent, resulted in the inhibition of the selenium delivery from the Hb-Se complex to the IOVs in a concentration-dependent manner [Fig. 4 (A)]. The treatments with iodoacetamide gave no remarkable changes in the binding affinity of the $\mathrm{Hb}-\mathrm{Se}$ complex for IOV (the binding constant: 1.64). The selenium delivery to IOVs was also inhibited by the pretreatment with $\alpha$-chymotrypsin ( $\alpha$-Chy) which selectively cleaves the Tyr359Lys360 bond of $N$-CPD [Fig. 4 (A)] [26]. The reverse treatment with $\alpha$-Chy (when the IOVs were first treated with the Hb-Se complex and then digested with $\alpha$-Chy) gave $\sim 50 \%$ selenium elimination [Fig. 4 (B)], which was similar to the result shown in Fig. 4 (A) (SDS-PAGE analyses of IOVs before and after the $\alpha$-Chy treatment were shown in Fig. S2). These results support the concept that Cys201 and Cys317 of $N$-CPD are implicated in the selenium delivery mechanism from the Hb-Se complex to the IOVs.

In addition, the selenium delivery was tested using IOVs that were prepared from the DIDS (4,4'diisothiocyanato-2,2'-stilbene disulfonate)-pretreated RBC. DIDS, an inhibitor of the anion exchange function of Band 3, binds to the membrane domain residues, Lys539 and Lys851, of the Band 3 protein 
and induces its conformational changes [27,28]. The amount of selenium delivered to the DIDSpretreated IOVs was less compared to the non-treated IOVs' [Fig. 4 (C)], indicating the participation of Band 3 in the selenium delivery.

To verify the results from our model experiments using PenGSSeSGPen and IOV, the unsealed membrane ghosts of the RBCs were treated with selenite and characterized. The treatment with $\alpha$-Chy afforded $\sim 50 \%$ release of the selenium bound to the membrane ghosts (Fig. 5), which matched the results from the model experiments (Fig. 4). While $\sim 50 \%$ of the membrane-bound selenium was located on $N$-CPD, the rest seems to be on the cytoplasmic domain of Band 3 other than $N$-CPD or other membrane components. To further explore the binding sites other than $N$-CPD, the membrane ghosts were treated with dithiothreitol which reductively cleaves di- and trisulfide bonds. The selenium bound was almost quantitatively eliminated from the membrane ghosts (Fig. 5), thus, indicating that the thiol groups on the inner surface of the RBC membrane participated in the selenium delivery by $\mathrm{Hb}$.

Band 3 contains two cytoplasmic domains; one is $N$-CPD and the other is the carboxy-terminal cytoplasmic domain (C-CPD, Asn880-Va1911) responsible for the anion exchange function [28]. It was recently reported that an assembly of $C$-CPD with the cytoplasmic moiety of glycophorin A (GPA) is another possible $\mathrm{Hb}$ binding site [29]. C-CPD also contains one free cysteine residue (Cys885) that is possible to react with the selenotrisulfide moiety $\left(\mathrm{GSSeS}^{-}\right.$) of the $\mathrm{Hb}$-Se complex, whereas GPA contains no cysteine residues in the cytoplasmic moiety. The mechanism underlying the selenium delivery to the $\mathrm{RBC}$ membrane by $\mathrm{Hb}$ may also involve the reactive cysteine residues of $C$-CPD of Band 3.

$\mathrm{Hb}$ molecules are present in three physiologically pertinent forms in the RBC (oxy-, deoxy- and ferri-Hb), and bind to $N$-CPD at physiological $\mathrm{pH}$ and ionic strength in an oxygen-linked fashion, with deoxy- and ferri-Hb having higher affinities for the RBC inner membrane [16,19]. Therefore, the ability of selenium delivery by $\mathrm{Hb}$ molecules to the IOVs was examined by varying the molar ratio of the oxy- to ferri-Hb-Se complexes. There were no differences in the amount of selenium bound to when the oxy- and ferri-Hb-Se complexes were used in this experiment, while the binding constant of oxy-Hb for the IOVs $\left(0.51 \pm 0.09 \mu \mathrm{M}^{-1}\right)$ was significantly lower than that of the ferri-Hb $(2.10 \pm 0.43$ $\left.\mu \mathrm{M}^{-1}\right)($ mean \pm s. e. $\mathrm{m}$., $P<0.05$, Fig. S6). The amount of selenium transferred to the IOVs increased with a decrease in the oxy-Hb-Se (or an increase in ferri-Hb-Se) fraction (Fig. 6). These data indicate that the selenium delivery by $\mathrm{Hb}$ to the inner surface of the $\mathrm{RBC}$ membrane is responsible for the $\mathrm{Hb}$ transition states.

When $\mathrm{Hb}$ in the $\mathrm{RBC}$ comes in contact with the capillaries in oxygen-metabolizing tissues, a large fraction of the $\mathrm{O}_{2}$ saturation is lost to the venous exchange. Practically, all $\mathrm{Hb}$ molecules are saturated 
by $\mathrm{O}_{2}$ in the alveoli of the lung while $\sim 70 \%$ of the $\mathrm{Hb}$ is deoxygenated in the active muscle capillaries due to the release of $\mathrm{O}_{2}$ [1]. To further verify the dependence of the selenium delivery on the $\mathrm{Hb}$ transition states, we examined the selenium export from the RBC to the plasma by continuously introducing $\mathrm{N}_{2}$ gas after the selenite treatment. The selenium content in the RBC significantly decreased due to $\mathrm{N}_{2}$ gas introduction, while the selenium amount exported to the plasma increased correspondingly (Fig. 7). Under the conditions used in this experiment, the oxy-Hb content in the RBC decreased from $91.4 \pm 1.5 \%$ before mixing with the plasma to $24.9 \pm 4.0 \%$ at $60 \mathrm{~min}$ after the incubation, whereas the fraction of the deoxy-Hb increased from $0.8 \pm 1.2 \%$ to $67.6 \pm 4.4 \%$. Thus, the selenium release from the RBCs to the plasma was facilitated by the increase in the deoxy-Hb fraction.

The data in this study support the concept that $\mathrm{Hb}$ involves the selenium delivery to the peripherals where the rate of the deoxy- $\mathrm{Hb}$ in the $\mathrm{RBC}$ becomes much higher than that of the oxy-Hb due to the oxygen release. Consequently, selenium supplied by selenite seems to be exported from the RBC to the plasma as follows: selenite is taken up into RBC and transformed into the Hb-Se complex via GSSeSG. Thereafter, the selenium bound to $\mathrm{Hb}$ is transferred to the RBC inner membrane surface based on the intrinsic interactions between $\mathrm{Hb}$ and the cytoplasmic domain of the Band 3 protein, and then exported to the peripheral blood and/or tissues. Accordingly, $\mathrm{Hb}$ molecules may respond to a reduction in peripheral $\mathrm{O}_{2}$ pressure with the release of selenium from the RBCs.

In the present study, we demonstrated that the interactions between the $\mathrm{Hb}$ molecule and the cytoplasmic domain of the Band 3 protein mediate the selenium delivery to the RBC plasma membrane and the subsequent export from the RBC. These observations indicate that selenium could possibly, in part, be exported to the peripheral blood and/or tissues by the $\mathrm{Hb}$ molecule in an oxygen-linked fashion. Selenium metabolites such as GSSeSG can be bound to a conserved thiol group (provided by Cys- $\beta 93$ in human $\mathrm{Hb}$ ), producing the selenium-bound $\mathrm{Hb}$. This could be followed by the selenium transfer to the Band 3 protein, with selenium departing from the RBC. This would preferentially occur in oxygenutilizing tissues, where deoxygenation triggers $\mathrm{Hb}$ to change its conformation from the oxygen-bound $\mathrm{Hb}$ structure to the deoxygenated one. As mentioned above, selenium is a critical element for the antioxidant defense against the oxidative damages to be generated by the respiration. Therefore, if the peripherals receive selenium from $\mathrm{Hb}$ together with $\mathrm{O}_{2}$ in defensive compensation for the oxidative damages, the concerted delivery of selenium and $\mathrm{O}_{2}$ to the peripheral blood and/or tissues may be a purposive function of $\mathrm{Hb}$. A better understanding of the systemic delivery mechanisms selenium from selenite is also of significance from the viewpoints of human medical treatments and toxicology [3]. Further experiments should focus on the elucidation of the in vivo selenium delivery by $\mathrm{Hb}$ to the peripheral blood and/or tissues in an oxygen-linked fashion. 


\section{References}

1. Stryer L (1995) Biochemistry Chapter 7. New York, NY: Freeman

2. Kryukov VG, Castellrano S, Novoselov SV, Labanov AV, Zehtab O, Guigo R, Gladyshev V. (2003) Science 300: 1439-1443

3. Rayman MR (2000) Lancet 356: 233-241

4. Mas A, Jiang J, Sarkar B. (1988) Biol. Trace Elem. Res. 15: 97-110

5. Suzuki KT, Shiobara Y, Itoh M, Ohmichi, M (1998) Analyst 123: 63-67.

6. Watkinson JH (1966) Anal. Chem. 38, 92-97.

7. Smith PK, Krohn RI, Hermanson GT, Mallia AK, Gartner FH, Paovenzano MD, Fujimoto EK, Goeke NM, Olson BJ, Klenk DC (1985) Anal. Biochem. 150: 76-85

8. Zijilstra WG, Buursma A, Meeuwsen-van der Roest WP (1991) Clin. Chem. 37: 1633-1638

9. Steck TL, Kant JA (1974) Methods Enzymol. 31: 173-180

10. Painter EP (1941) Chem. Rev. 28, 179-213

11. Lindemann T, Hintelmann H (2002) Anal. Chem. 74: 4602-4610

12. Haratake M, Fujimoto K, Ono, M, Nakayama M (2005) Biochim. Biophys. Acta 1723; 215-220

13. Ganther HE (1971) Biochemistry 10: 4089-4098

14. Self WT, Tsai L, Stadtman TC (2000) Proc. Natl. Acad. Sci. U. S. A. 97: 12481-12486

15. Kaul RK, Kohler H (1983) Klin. Wochenschr. 61: 831-837

16. Walder JA, Chatterjee R, Steck TL, Low PS, Musso GF, Kaiser ET, Rogers PH, Arnone A (1984) J. Biol. Chem. 259: 10238-10246

17. Salhany JM, Cordes KA, Gains ED (1980) Biochemistry 19: 1447-1454

18. Demehin AA, Abugo OO, Jayakumar R, Lakowica JR, Rifkind LM (2002) Biochemistry 41: 86308637

19. Chetrite G, Cossoly R (1985) J. Mol. Biol. 185: 639-644

20. Rauenbuehler PB, Cordes KA, Salhany JM (1982) Biochim. Biophys. Acta 692: 361-370

21. Salhany JM, Cossoly R (1989) J. Biol. Chem. 264: 1399-1404

22. Langmuir I (1917) J. Am. Chem. Soc. 39: 1848-1906

23. Sayare JM, Fikiet M (1981) J. Biol. Chem. 256: 13152-13158

24. Pawloski JR, Hess DR, Stamler JS (2001) Nature 409: 622-626

25. McMahon TJ, Moon RE, Luschinger BP, Carraway MS, Stone AE, Stolp BW, Gow AJ, Pawloski

JR, Watke P, Singel DJ, Piantadosi CA, Stamler JS (2002) Nat. Med. 8: 711-717

26. Steck TL, Fairbanks G, Wallach FH (1971) Biochemistry 10: 2617-2624

27. Salhany JM (2001) Blood Cells Mol. Dis. 27: 127-134 
28. Popv M, Tam LY, Li J, Reithmeier RAF (1997) J. Biol. Chem. 272: 18325-18332

29. Fu G, Wang T, Yang B, Lv F, Shi C, Jiang X, Tian F, Yu W, Hamasaki N (2004) Biochemistry 43: $1633-1638$ 
(A)
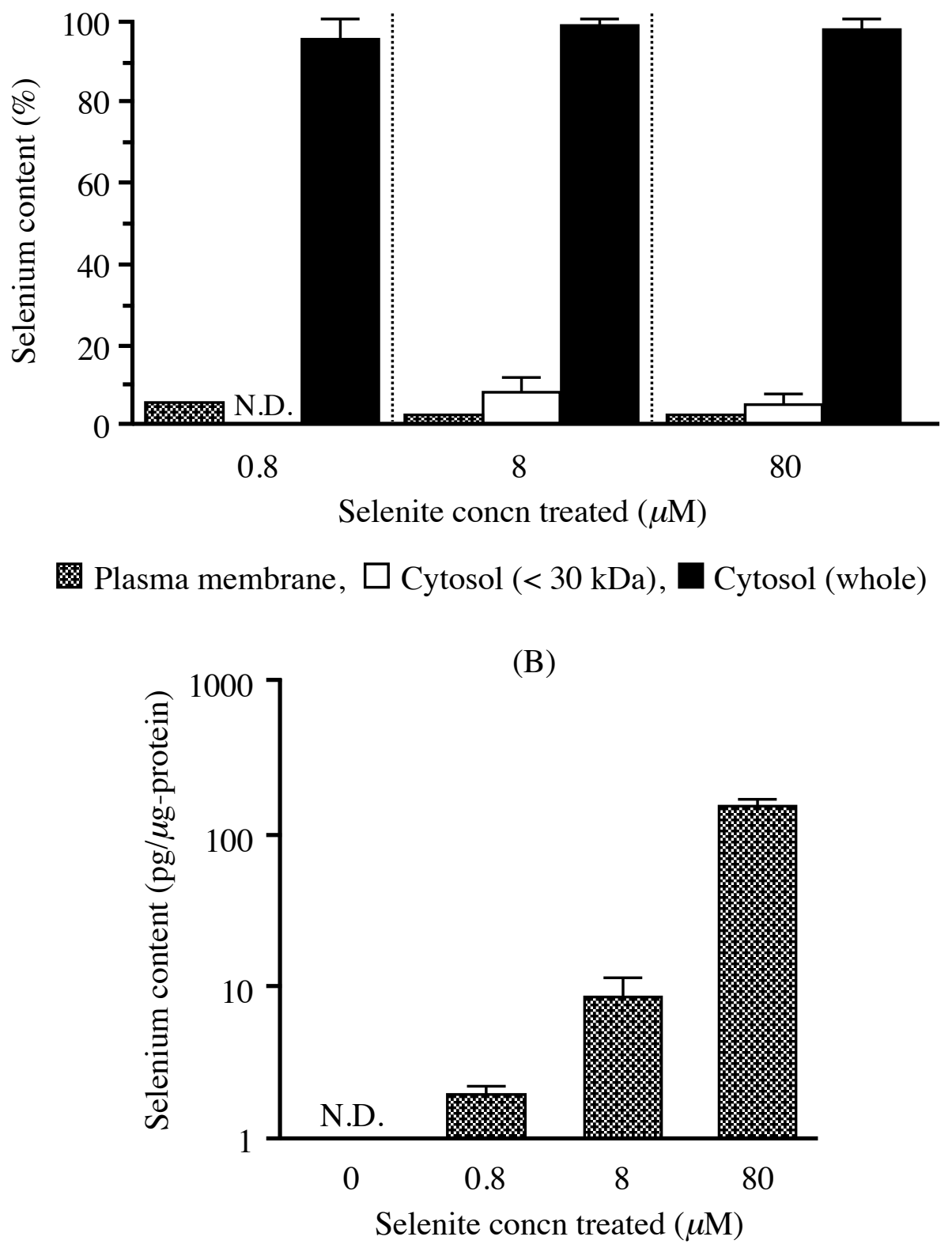

Fig. 1 (A) Selenium distribution in RBC after the treatment with selenite. The RBCs were incubated with selenite $(0.8-80 \mu \mathrm{M})$ in isotonic phosphate buffer $(\mathrm{pH} 7.4)$ at $37^{\circ} \mathrm{C}$ for $10 \mathrm{~min}$ to a hematocrit of $20 \%(\mathrm{v} / \mathrm{v})$. The selenite-treated RBCs were hemolyzed and centrifuged at 22,000 $\mathrm{g}$ for $15 \mathrm{~min}$. The obtained supernatant was further ultrafiltered using an Ultrafree ${ }^{\circledR}-\mathrm{MC}$. The selenium contents of the supernatant (whole cytosol), the red pellets (the plasma membrane) and the filtrate (molecular weight less than $30 \mathrm{kDa}$ in the cytosol) were measured. (B) Selenium contents in the plasma membrane after the treatment of selenite. The RBCs [hematocrit $20 \%(\mathrm{v} / \mathrm{v})]$ were incubated with selenite $(0.8-80 \mu \mathrm{M})$ in isotonic phosphate buffer $(\mathrm{pH} \mathrm{7.4)} \mathrm{for} 10 \mathrm{~min}$. The selenite-treated RBCs were hemolyzed and centrifuged at $22,000 \mathrm{~g}$ for $15 \mathrm{~min}$. The precipitated red pellets were thoroughly washed with 5 and 0.5 
$\mathrm{mM}$ phosphate solution $(\mathrm{pH} \mathrm{8})$ to remove the membrane-bound $\mathrm{Hb}$. Data are mean \pm s. e. m., $\mathrm{n}=5 . \mathrm{n}$. d.; not detected. 
(A)<smiles>CC(C)(S[Se]S[C@@H](NC(=O)CC[C@H](N)C(=O)O)C(C)(C)[C@H](NC(=O)CC[C@H](N)C(=O)O)C(=O)NCC(=O)O)C(=O)NCC(=O)O</smiles>

(B)

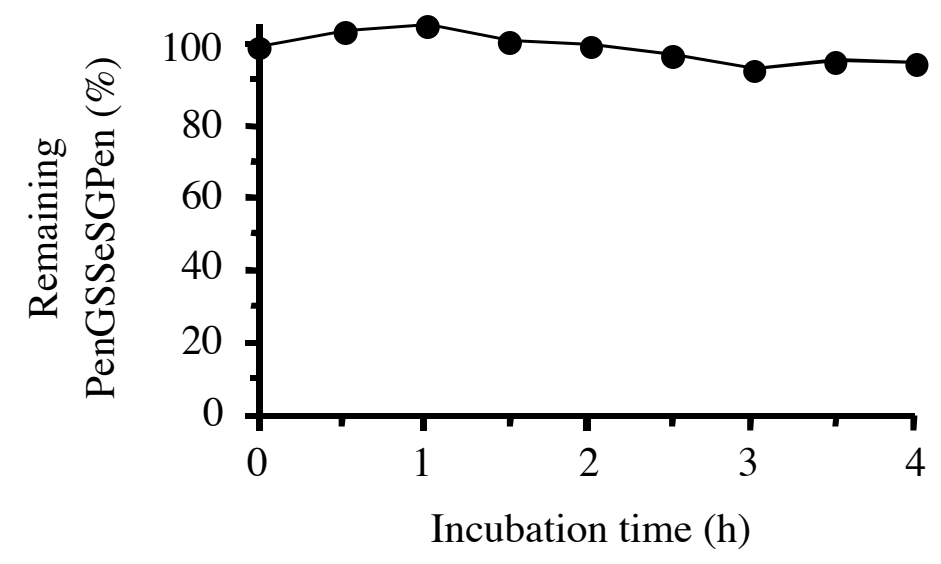

(C)

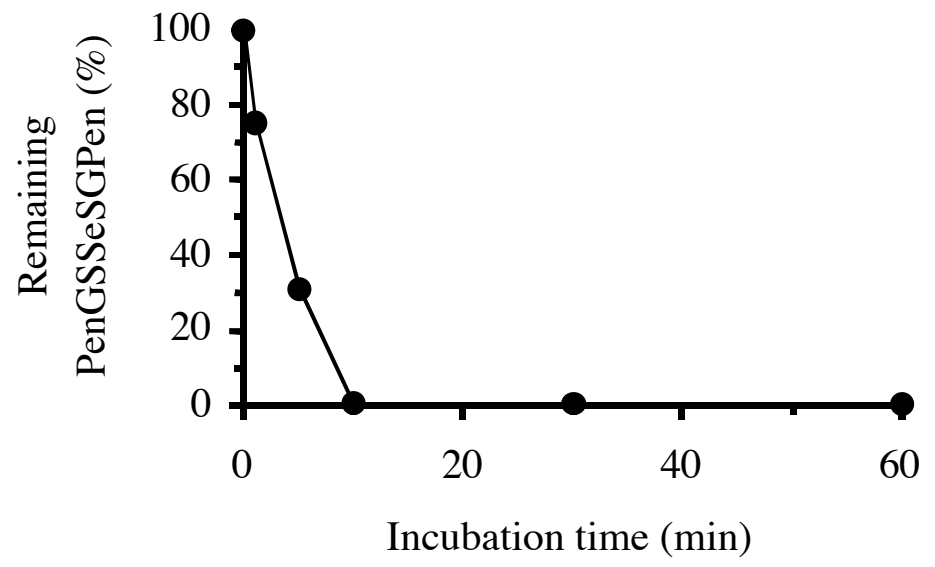

Fig. 2 (A) Chemical structure of PenGSSeSGPen. (B) Chemical stability of PenGSSeSGPen (100 $\mu \mathrm{M})$ in isotonic phosphate buffer (pH 7.4) at $37^{\circ} \mathrm{C}$. (C) Reaction of PenGSSeSGPen $(20 \mu \mathrm{M})$ with Hb $(200$ $\mu \mathrm{M}$ ) in isotonic phosphate buffer ( $\mathrm{pH} 7.4$ ) at $37{ }^{\circ} \mathrm{C}$. Remaining PenGSSeSGPen was determined by RPLC. 


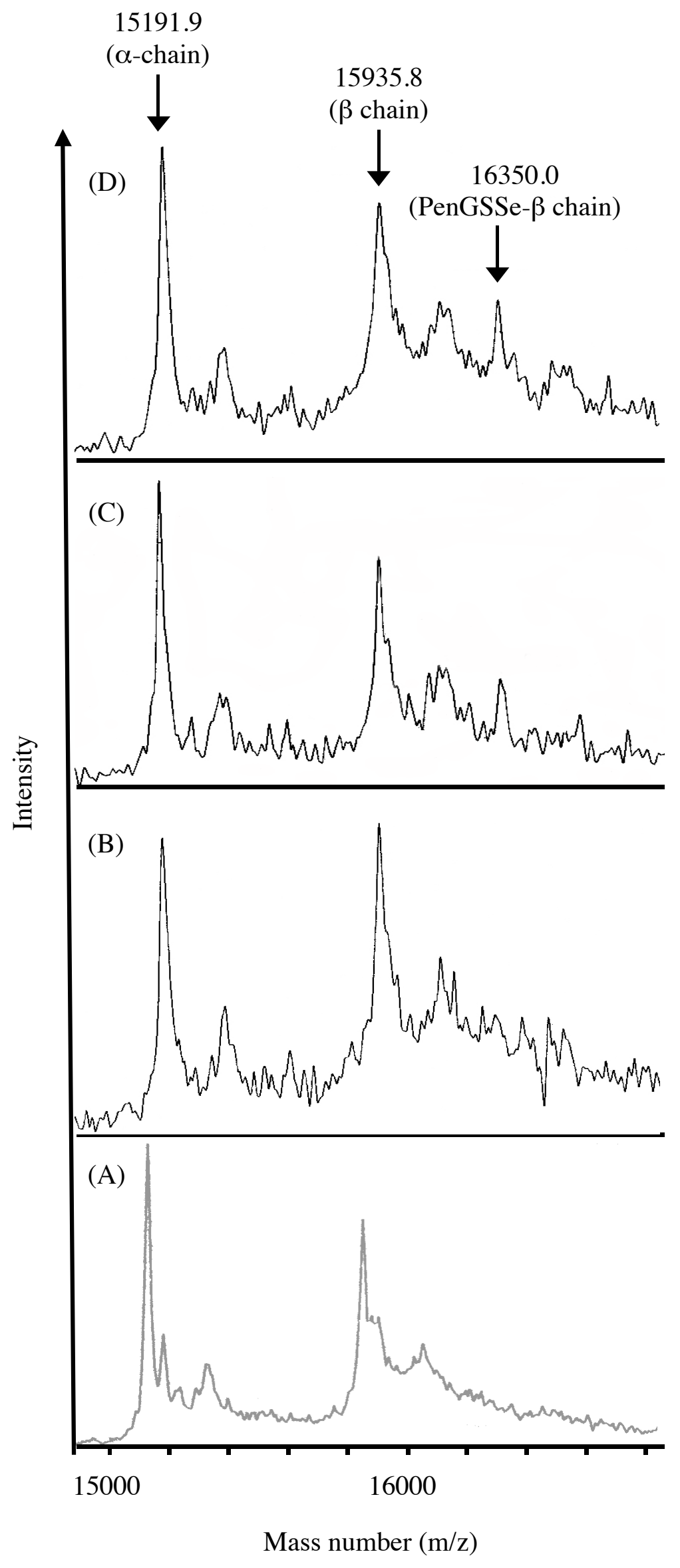


Fig. 3 MALDI-TOF mass spectra of $\mathrm{Hb}$ treated with increasing PenGSSeSGPen concentrations. Hb to PenGSSeSGPen concentration ratio (A) $1: 0$, (B) $1: 5$, (C) $1: 10$, (D) $1: 20$. Hb $(5 \mu \mathrm{M})$ was treated with varying concentration ratio of PenGSSeSGPen in deionized water at $37{ }^{\circ} \mathrm{C}$ for $10 \mathrm{~min}$. The sample solutions were combined with the matrix solution [sinapinic acid in $34 \%(\mathrm{v} / \mathrm{v})$ acetonitrile and $20 \%$ (v/v) trifluoroacetic acid] by one to ten volume ratios, and an aliquot was applied on an AnchorChip $^{\circledR}$ target (Bruker Daltonics Inc, USA). The mass spectra were obtained using an Ultraflex (Bruker Daltonics Inc, USA), operated in the linear positive ion mode. The molecular mass calibration was accomplished using a \#206355 Protein Calibration Standard (Bruker Daltnics, Inc, USA). 
(A)

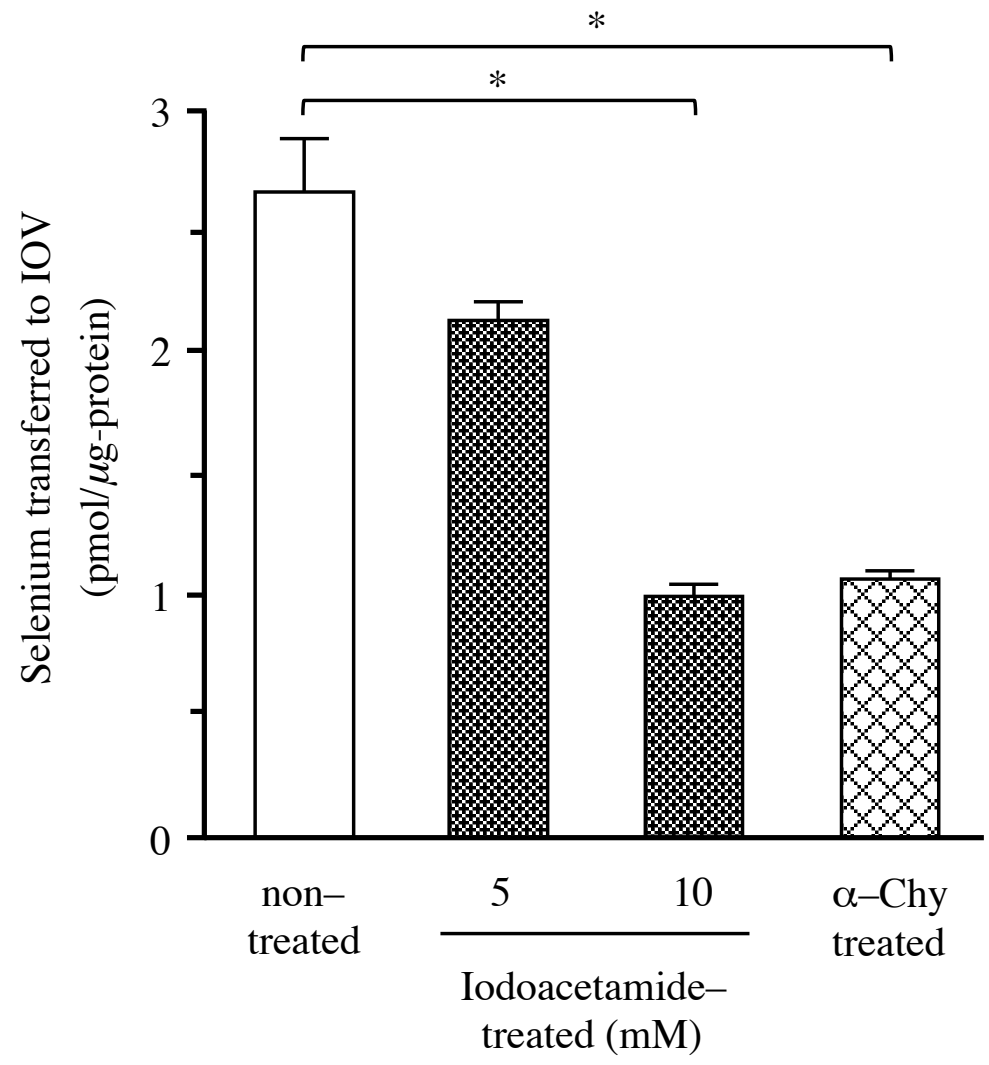

(B)
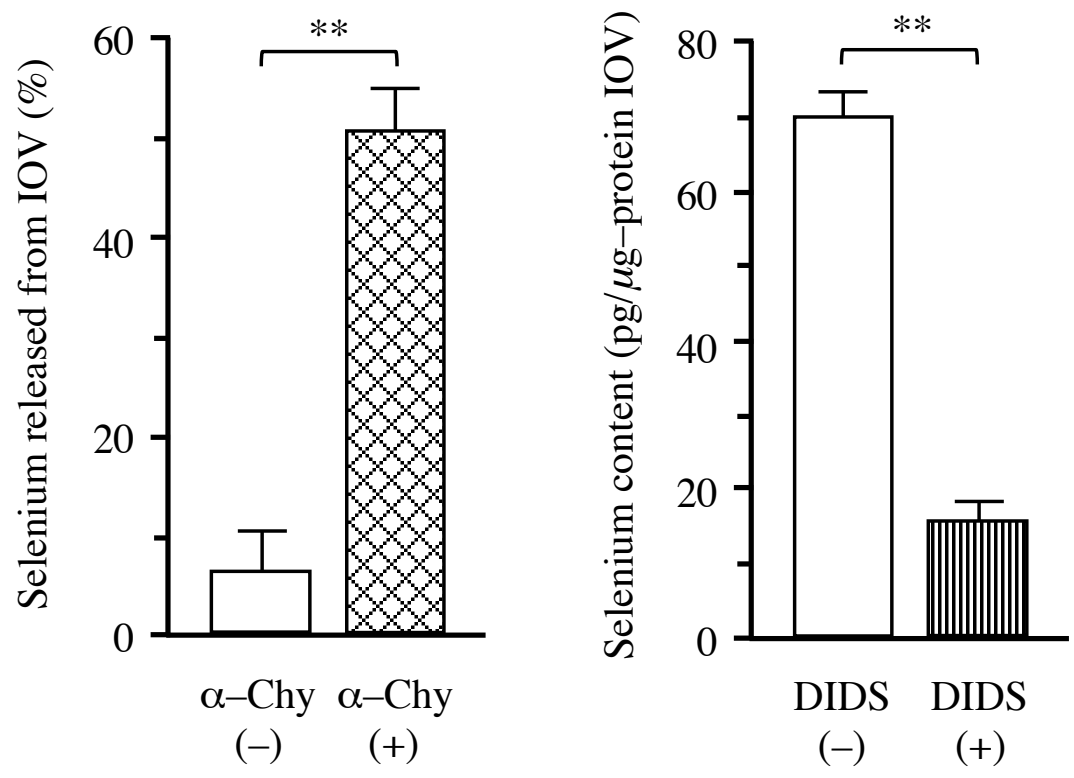

Fig. 4 (A) Inhibitory effects of iodoacetamide and $\alpha$-Chy on the selenium delivery from $\mathrm{Hb}$-Se complex to IOVs. Non-treated and iodoacetamide (5 and $10 \mathrm{mM})$ or $\alpha$-Chy $(200 \mu \mathrm{g} / \mathrm{mL})$-pretreated IOVs $(170 \mu \mathrm{g}$-protein $/ \mathrm{mL})$ were combined with the Hb-Se complex $(1 \mu \mathrm{mol}-\mathrm{Hb} / \mathrm{L})$ in $0.01 \mathrm{M}$ phosphate buffer $(\mathrm{pH} \mathrm{6)}$. After centrifugation at 22,000 $\mathrm{g}$ for $15 \mathrm{~min}$, the precipitated IOVs were 
washed with $0.02 \mathrm{M}$ phosphate buffer $(\mathrm{pH}$ 8) containing $0.5 \mathrm{M} \mathrm{NaCl}$ and their selenium contents were determined by the DAN method. (B) Selenium delivery from the Hb-Se complex to $\alpha$-Chy-pretreated IOVs. IOV suspension $(170 \mu$ g-protein $/ \mathrm{mL})$ was pretreated with the $\mathrm{Hb}$-Se complex $(1 \mu \mathrm{mol}-\mathrm{Hb} / \mathrm{L}) \mathrm{in}$ $0.01 \mathrm{M}$ phosphate buffer ( $\mathrm{pH}$ 6) at room temperature. After centrifugation at 22,000 $\mathrm{g}$ for $15 \mathrm{~min}$, the precipitated IOVs were washed three times with $0.02 \mathrm{M}$ phosphate buffer ( $\mathrm{pH} 8$ ) containing $0.5 \mathrm{M}$ $\mathrm{NaCl}$ to remove the membrane-bound $\mathrm{Hb}$ and $\mathrm{Hb}$-Se complex. The Hb-removed IOVs were treated with $\alpha$-Chy $(200 \mu \mathrm{g} / \mathrm{mL})$ in $0.01 \mathrm{M}$ phosphate buffer $(\mathrm{pH} 7.4)$ at $37{ }^{\circ} \mathrm{C}$, and centrifuged at $22,000 \mathrm{~g}$ for 15 min. The selenium contents in the washing buffer and IOV were determined by the DAN method. The selenium content of the IOV before the removal of $\mathrm{Hb}$ was defined as $100 \%$. (C) Effect of DIDS on selenium delivery from Hb-Se complex to IOVs. RBCs were pretreated with $100 \mu \mathrm{M}$ selenite, and the obtained IOVs were treated with $50 \mu \mathrm{M}$ DIDS. Data are mean \pm s. e. $\mathrm{m} ., \mathrm{n}=5$. ${ }^{*} ; P<0.05,{ }^{*} ; P<$ 0.01 . 


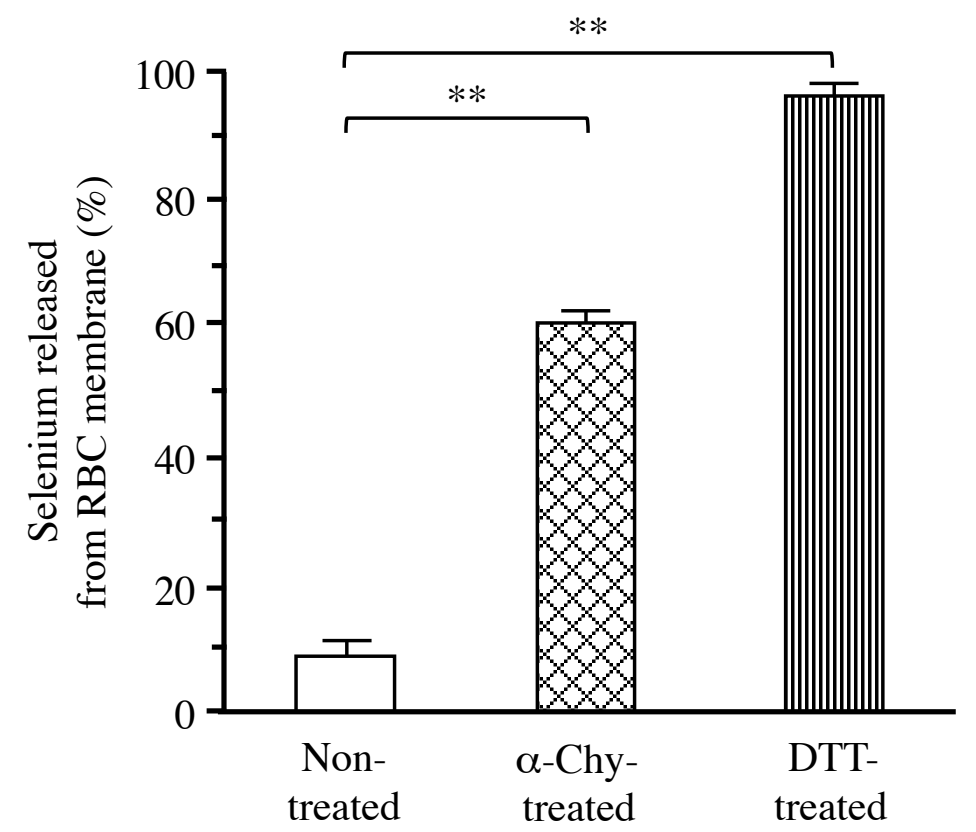

Fig. 5 Selenium release from selenite-treated RBC membrane ghosts by $\alpha$-Chy and dithiothreitol treatments. The isolated RBCs [hematocrit $20 \%(\mathrm{v} / \mathrm{v})$ ] were incubated with selenite $(80 \mu \mathrm{M})$ in isotonic phosphate buffer $(\mathrm{pH} 7.4)$ at $37{ }^{\circ} \mathrm{C}$ for $10 \mathrm{~min}$. The selenite-treated RBCs were hemolyzed and centrifuged at $22,000 \mathrm{~g}$ for $15 \mathrm{~min}$. The precipitated red pellets were thoroughly washed with 5 and $0.5 \mathrm{mM}$ phosphate solution ( $\mathrm{pH} 8$ ) to remove the membrane-bound $\mathrm{Hb}$. The Hb-free white $\mathrm{RBC}$ membrane ghosts were treated with $\alpha$-Chy $(200 \mu \mathrm{g} / \mathrm{mL})$ or dithiothreitol $(2 \mathrm{mM})$ in $0.01 \mathrm{M}$ phosphate buffer ( $\mathrm{pH} \mathrm{7.4)}$ at $37{ }^{\circ} \mathrm{C}$ for $10 \mathrm{~min}$, and centrifuged again at 22,000 $\mathrm{g}$ for $15 \mathrm{~min}$. The selenium contents in the washing buffer and $\mathrm{RBC}$ membrane were determined by the DAN method. The selenium content of the RBC membrane before treatment was defined as $100 \%$. Data are mean $\pm \mathrm{s}$. e. m., $\mathrm{n}=5 .{ }^{* *} ; P<0.01$. 


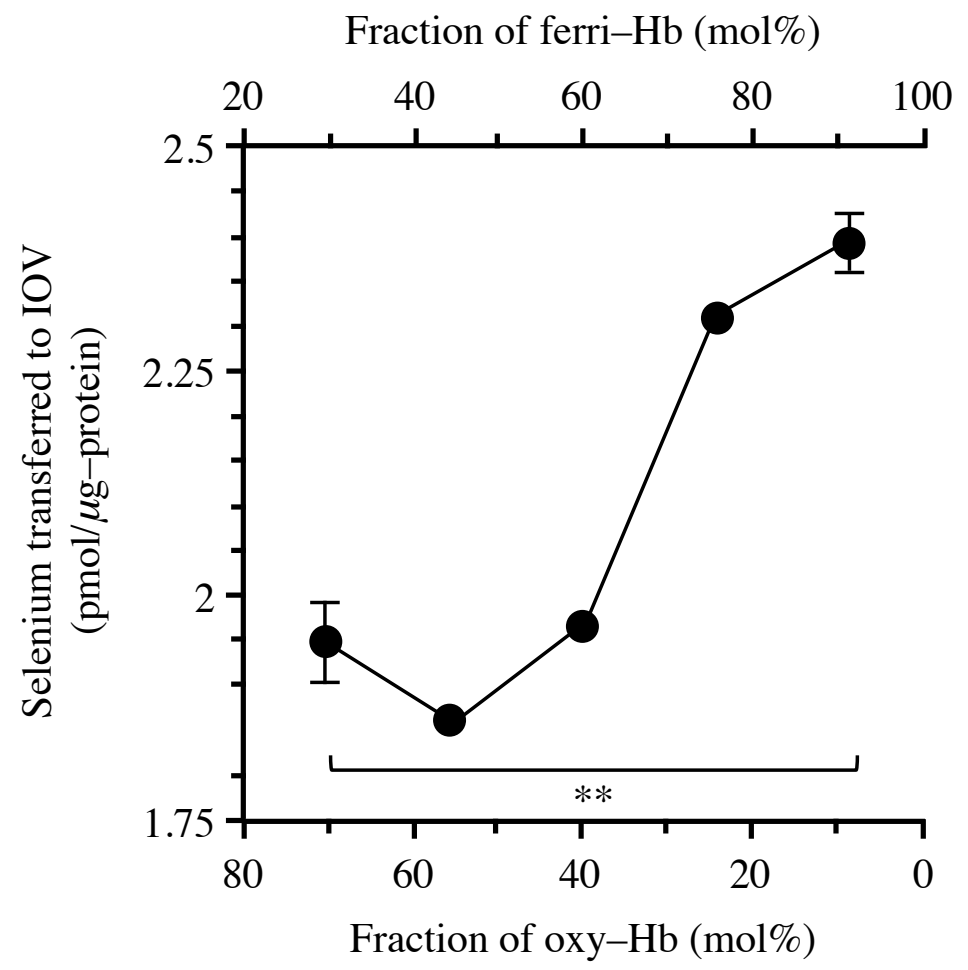

Fig. 6 Effect of the transition form of $\mathrm{Hb}$ on the selenium delivery from the $\mathrm{Hb}-\mathrm{Se}$ complexes to the IOVs. An IOV suspension (170 $\mu$ g-protein $/ \mathrm{mL}$ ) was co-incubated with mixtures of the oxy-Hb- and ferri-Hb-Se complexes ( $1 \mathrm{mmol}-\mathrm{Hb} / \mathrm{L}$ ) at various ratios (oxy- $\mathrm{Hb} ; 10-70 \mathrm{~mol} \%$, ferri-Hb; 30-90 mol\%) in $0.01 \mathrm{M}$ phosphate buffer ( $\mathrm{pH} \mathrm{6}$ ) at $37{ }^{\circ} \mathrm{C}$ for $10 \mathrm{~min}$. After centrifugation at 22,000 $\mathrm{g}$ for $15 \mathrm{~min}$, the precipitated IOVs were washed with $20 \mathrm{mM}$ phosphate buffer $(\mathrm{pH} 8)$ containing $0.5 \mathrm{M} \mathrm{NaCl}$ and their selenium contents were determined by the DAN method. Data are mean $\pm \mathrm{s}$. e. m., $\mathrm{n}=4$. **; $P<0.01$. 


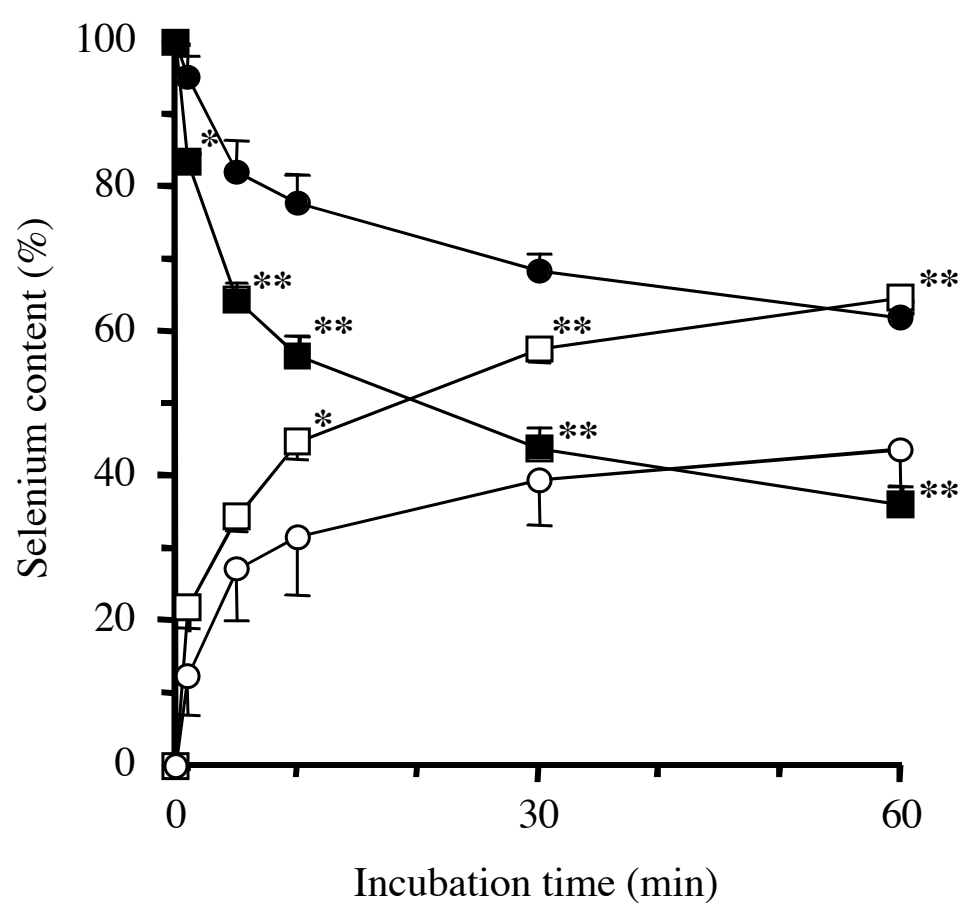

Fig. 7 Effects of nitrogen gas introduction on the selenium release from the selenite-treated RBCs to the plasma. $\square, \mathrm{RBC}$ with $\mathrm{N}_{2}$ gas; $\square$, plasma with $\mathrm{N}_{2}$ gas; $\boldsymbol{O}$, RBC without $\mathrm{N}_{2}$ gas; $\bigcirc$, plasma without $\mathrm{N}_{2}$ gas. The RBCs [hematocrit $20 \%(\mathrm{v} / \mathrm{v})$ ] were incubated with selenite $(8 \mu \mathrm{M})$ in isotonic phosphate buffer $\left(\mathrm{pH} \mathrm{7.4)}\right.$ ) at $37^{\circ} \mathrm{C}$ for 10 min. The selenite-treated $\mathrm{RBCs}$ and the plasma that was pretreated with or without $\mathrm{N}_{2}$ gas for 30 min were combined [hematocrit $20 \%(\mathrm{v} / \mathrm{v})$ ] and then incubated at $37{ }^{\circ} \mathrm{C}$ for the indicated time. The selenium contents in RBCs before incubation with the plasma were defined as $100 \%$. Data are mean \pm s. e. $\mathrm{m} ., \mathrm{n}=17$. Significantly different from the corresponding time points of the $\mathrm{N}_{2}$ gas-free experiment, $* ; P<0.05$, **; $P<0.01$. 


\section{Supplementary material}

Fig. S1 Reversed-phase liquid chromatographic analysis of reaction mixture of selenite and PenGSH and absorption spectrum of isolated PenGSSeSGPen

Fig. S2 SDS-PAGE of IOVs

Fig. S3 Circular dichroism spectra of ferri-Hb-Se complex and ferri-Hb

Fig. S4 Langmuir plots for binding of $\mathrm{Hb}(\mathrm{A})$ and ferri-Hb-Se complex (B) to IOV

Fig. S5 $\mathrm{Hb}$ mediated-selenium binding to IOV

Fig. S6 Langmuir plots for binding of oxy-Hb prepared from RBC and ferri- $\mathrm{Hb}$ to IOV. 